\title{
Da memória e seus disturbios
}

\author{
Prof. A. C. Pacheco e Silva \\ Catedrático de Clínica Psiquiátrica.
}

Que é memória? Janet, no seu livro sôbre a evolução da memória e a noção do tempo, se estende em considerações sôbre essa questão, reconhecendo a extrema dificuldade de se definir exatamente o que vem a ser a memória.

E' a lembrança dos fátos passados, é um mecanismo psiquico, de ordem biológica sem dúvida, extremamente complexo, que nos permite não só fixar uma nova impressão, como ainda conservá-la, reproduzi-la quando desejamos e, ainda mais, localizar no tempo o momento em que a mesma se verificou.

Não se póde empreender em nossos dias um estudo sôbre a memória e seus distúrbios sem se deter longamente sôbre os trabalhos fundamentais de Th. Ribot, a quem devemos uma das leis que regem o apagamento das faculdades mnésicas, dita lei de Ribot ou da regressão da memória, que foi, por assim dizer, o ponto de partida inicial para os esturos que posteriormente se fizeram sôbre êsse momentoso problema. Não se pense, entretanto, constituir o estudo da memória preocupação apenas dos autores modernos. Já na mais remota antiguidade - conta-nos Ramon y Cajal no seu livro "O mundo visto por um artério-esclerótico" ao se referir às atribulações de um ancião quando percebe o apagamento da memória, - constituiam as investigações sôbre a memória preocupação constante dos filósofos gregos. Estes já a haviam divinisado, reconhecendo ser a memória a faculdade principal, sôbre a mesma se assestando todas as demais, quér intelectuais como afetivas. Por isso a denominaram Mnémosina, isto é, a Mãe das Musas, da Mitologià Grega, Imagem simbólica que serve bem para demonstrar. como já se considerava, naquela época, a memória como a faculdade básica que serve de sustentáculo a lodas as demais. 
Revista de Medicina

Vejamos, cll rápida sintese, como se poderá empreender o enludo das diversas modalidades da memória e quais os principais elementos de que dispomos para estabelecer uma classificação. um fio condutor que nos permita não só ordenar, como ainda metodizar os diversos distúrbios mnésicos.

Para que unn fílo possa ser recordado, para que uma lembrança scja evocada. nio hasta que uma determinada impressão faça vibrar os nossos sentidos. E' preciso, também. que a sensaçào percebida permaneça fixada, integrada, incrustada, na expressão de Ribot, dentro do nosso cérebro. Dai se depreende ser imprescindivel a conservação da imagem fixada. Mas de nada adiantaria a imagem permanecer dormitando nos elementos nobres do sistema nervoso, sem que nos fosse possível dela nos utilizarmos quando tivessemos necessidade ou quando por um esfôrço da nossa vontade quisessemos trazé-la à tơna da nossa conciência. Isso eqüivaleria a se dispór de um vasto arquivo, sen índice, conservado eln desordem, sem classificação. Num dado momento, quando nos vissemos obrigados a recorrer aos documentos nele conservados, embóra tivessemos a certeza de alí se encontrar o que descjavamos, não nos seria possível descobrir, quando houvesse urgència, do que careciamos. Ora, a memória $\dot{e}$ um arquivo cuja organização precisa ser perfeita, por-isso-que na elaboração do pensamento os dados de que carecemos devem surgir rapidamente à tona da conciência, sem o que haveria entrave no nosso raciocínio, na nossa imaginação e não nos seria possivel realizar uma operação intelectual, por mais simples que fosse, sem constantes interrupçōes, para se proceder à busca da lembrança fixada e conservada. Dai decorre a terceira modalidade da memória, a de evocação ou de reprodução. Finalmente, seria suficiente dispormos da capacidade de fixação, conservação e reprodução? Evidentemente que não! Há um outro imperativo, sem o que a memória se estabeleceria de um modo ainda confuso. Impõe-se, ao demais, a localização da memória no tempo, há necessidade de se estabelecer uma ordem cronológica, de forma a nos permitir prontamente saber si determinado fáto, agora evocado, se verificou antes, depois ou concomitantemente a outro com êle relacionado.

Sem isso se estabeleceria um baralhamento nas nossas faculdader mnésicas e não nos seria possível reconstituir a nossa vida pregressa, os dados intelectuais, as impressões 
visuais ou auditivas, em uma palavra todo o nosso passado. Expostas, assim, ligeiramente, as diversas formas da memória, cujos distúrbios constituem os elementos básicos que nos permitem distinguir as diversas amnésias, vamos agora sintetizar o que se pode chamar a semiologia da memória.

No desenvolvimento dêste estudo recorremos aos trabalhos de Ribot, Janet, Dugas, Dromard, Lugaro, Morselli, Kraepelin, sem contudo nos filiarmos a esta ou àquela dudtrina, buscando traçar uma diretriz com dados colhidos aqui e alí, de acôrdo com o que nos pareceu mais didático.

Ao se iniciar o estudo das desordens da memoria, há a se considerarem as modificações que podem atuar sòbre a mesma de um modo quantitativo. Assim, de uma forma geral, a memória num determinado caso pode se apresentar abolida (amnésia), diminuida (hipomnésia), aumentada (hipermnésia) e finalmente pervertida (dismnésia).

Todas as outras modificações que se verificam podem ser enquadradas dentro destas quatro divisões, segundo a opinião dos autores acima citados.

HIPOMNÉSIA. - Verifica-se a diminuição da memória abrangendo um vasto campo da vida psiquica ou um limitado círculo da mesma. Assim, pode a diminuição da memória ser geral ou parcial. Há doentes mentais ou mesmo pessoas normais que em virtude de condições especiais - cansaço, intoxicações, convalescenças de doenças infectuosas, etc. revelam extraordinária dificuldade em reter números, côres, etc., ao passo que manifestam relativa integridade para reter fátos em que não há a intromissão de números ou de côres. Na epilepsia e na confusão mental são muito freqüentes as hipomnésias, tanto gerais como circunscritas a determinados fátos ou categoria de elementos. Os autores italianos, entre os quais Morselli, entendem que não há hipomnésias puras, pois que quando há diminuição da memória o individuo procura inconcientemente substituir as lacunas suprindo pela imaginação, deformando assim os acontecimentos. As perturbações por insuficiência (hipomnésia) se transformariam, dêsse modo, em distúrbios por perversão (dismnésia).

AMNESIAS. - São as amnésias as principais perturbações da memória e o seu estudo exige cuidado e atenção, em virtude de se estabelecerem numerosos diagnósticos diferenciais, prognósticos relacionados com doenças mentais, basea- 
dos tĩo somente na forma pela qual se nos apresenta uma determinada amnésia.

Dromard entende fundamental a distinção a se fazer inicialmente: - Trata-se de uma amnésia funcional ou orgánica? O distúrbio observado prende-se a um simples desarranjo no mecanismo psíquico, na associação ideativa, ou há a inıpossibilidade orgânica de se reproduzir determinada sensação em virtude da destruição dos elementos nobres do sistema nervoso, das células que seriam, no dizer de Ribot, as placas sensiveis que guardam as impressões, ou ainda das fibras que permitenı se estabeleça conexão entre as imagens retidas pelas células? Devemos reconhecer que, si $\mathrm{cm}$ certos doentes nos é possível filiar a perturbação da memória a este ou àquele fator, estabelecer-se, por assim dizer, a sua patogenia, tal não ocorre em muitos casos.

Estabelecido tratar-se de uma perturbação orgânica, seria útil apurar-se si a impossibilidade decorre de uma insuficiència congênita, ligada a uma malformação do encéfalo ou si o transtòrno mnésico se prende a um processo mórbido em evolução que tenha determinado a destruição do parênquima nervoso. No primeiro caso teriamos "os oligofrénicos, que jamais tiveram armazenados elementos mnésicos, por vicio constitucional que impediu a assimilação de conhecimentos colhidos no mundo exterior. No segundo, estariamos diante de um estado demencial, de um enfraquecimento psiquico condicionado por um processo destrutivo do tecido nervoso.

As amnésias conforme o grau: - De acôrdo com o grau da amnésia esta pode ser geral ou parcial. Diz-se que há aninésia geral quando o cancelamento da memória abrange todas as reminiscências, ao passo que há ámnésia parcial quando os conhecimentos olvidados atingem apenas determinada série de recordações. Na psicastenia e nos estados confusionais é que se vão buscar exemplos destas duas formas de amnésia, porquê é nesses estados que êles se apresentam com maior freqüência.

Duração: - Conforme a sua duração, as amnésias se subdividem em passageiras, duradouras ou definitivas. Há amnésia passageira quando a perda dos elementos mnésicos se desvanece rapidamente. Tal é o caso de um epilético que, passada a crise convulsiva, se apresenta em estado crepuscular e é incapaz de se recordar da incidência da crise e das 
circunstâncias que a cercaram. Entretanto, passado algum tempo, variável em cada individuo e num mesmo doente diversa conforme as crises, a lembrança dos acontecimentos se vai restabelecendo, por tal forma que ao fim de algumas horas, em regra, terá o indivíduo recuperado de novo todas as lembranças olvidadas. "Casos há em que o restabelecimento das faculdades mnésicas não se opera rapidamente, mas sim mui lentamente, sendo necessários dias, semanas e até meses para que se restabeleça, gradual e morosamente, a memória. (Ex.: - estados confusionais).

Finalmente, registra-se ainda uma forma de amnésia, dita definitiva, em que uma vez perdida a faculdade mnésica não há mais possibilidade de retôrno da mesma. Tal se dá quando há uma lesão orgânica, uma destruição dos tecidos nervosos, com devastação celular, não havendo possibilidade de se reconstituirem as imagens, verdadeiros moldes que se não podem refazer, por-isso-que as células nervosas se não multiplicam e uma vez destruidas são substituidas pela glia. que constitue o elemento cicatricial. Isso ocorre na paralisia geral, na demência senil e vem demonstrar, como já afirmava Ribot e ainda afirma Bergson no seu livro "Natiere et Memoire", ser a memória uma função essencialmente orgânica.

Si na criança tudo se cinge a um áto elementar, mais tarde, à medida que os nossos conhecimentos se vão dilatando, o mecanismo mnésico se vai tornando extremamente complexo, dada a intervenção de um sem número de imagens e sensações novas, nem por isso deixa de ser um fenómeno biológico.

Evolução: - Conforme a evolução da amnésia, esta pode ser subdividida em súbita e insidiosa. Quando se verifica um traumatismo cerebral, ou um dos chamados ictus mnésicos, como é freqüente nos grandes abalos morais, o paciente sofre uma perda brusca, subitânea das lembranças. Outras vezes o que se observa é um desaparecimento lento, progressivo das recordações. Costuma-se citar como exemplo de perda insidiosa da memória a que é.notada nos paralíticos gerais.

Ainda uma terceira categoria é descrita neste grupo. São as amnésias periódicas, que sobrevêm intermitentemente. Em certos momentos o paciente evoca, sem acusar maior dificuldade, os acontecimentos passados, para logo depois nāo lograr reconstitui-los. Esta forma pode ser encontrada 
nas toxicomanias, em que o indivíduo sob a ação do tóxico, estimulado, pode se lembrar dos fátos desenrolados no decurso da sua vida, relatando as menores minúcias, ao passo que. na fase de abstinência tudo se lhe afigura sem relêvo, obscuro, nao the sendo possivel, por maiores esforços que faça, lembrar-se das ocorrências passadas.

Relação cronológica: - A memória nos permite localizar os fátos no tempo. Assim, tambẻm as amnésias podem se relacionar conforme o esquecimento se limita aos fátos passados, aos recentes ou a ambos conjuntamente. A observação que permitiu o exáto conhecimento dêste fáto é devida a Koempfen. Este médico, que servia junto a um regimento de cavalaria, observou certo dia um oficial que durante os exercicios sofrera uma quéda sôbre o crâneo, ficando ligeiramente atordoado. Não obstante, prosseguiu nos exercícios. Ao depois, embóra nâo manifestasse outros sịntomas, não sc recordava da quéda, assim como do que havia feito nos dias anteriores ao do acidente. Só passado algum tempo foi se refazendo a lembrança dos fátos ocorridos antes do tombo. Dessa observação, foi possivel desdobrar-se, afirma Ribot, a amnésia en dois grupos. A retrógrada, que abrange os conhecimentos anteriores a um determinado acidente mnésico, e a anterógrada, que compreende os fátos ocorridos após o mesmo.

Há casos em que ambas as formas se apresentam conjuntamente; diz-se então que há uma amnésia retro-anterógrada.

A amnésia retrógrada seria, sobretudo, uma amnésia de evocação, ao passo que a anterógada seria de fixação. No caso de haver o olvido de ambas as fases que antecederam e sucederam o fator determinante da amnésia, dar-se-á uma amnésia retro-anterógrada.

As alterações da memória podem tambem cingir-se a certas modalidades, determinados atributos da memória. 0 vulgo conhece os predicados de certas pessoas que fixam indelevelmente as impressões visuais, outras revelam maior facilidade em fixar as auditivas.

Assim também com relação às amnésias.

Muitas vezes a dificuldade de fixação, a de evocação, de sensações anteriormente percebidas concerne apenas às impressões visuais, auditivas, tatis, etc. Diz-se então que há amnésia visual, auditiva, etc., conforme a esfera atingida. 
HIPERMNÉSIAS - Estudadas as amnésias, que constituem o capítulo mais importante da semiologia da memória, convém fazer agora breve relato das chamadas hipermnésias, em que há uma exaltação da memória, não só pela reviviscência dos fátos que pareciam esquecidos, como ainda pela superabundância de minúcias com que se apresentam as imagens facilmente evocadas, pois que as impressões surgem quasi que automaticamente à tona da conciência.

Nos febrís, à super-excitação provocada pela circulação cerebral mais rápida e mais intensa verifica-se êsse fenômeno. Diz-se que Walter Scott escreveu várias das suas ubras quando sob a ação da febre, pois que sentia então a sua imaginação povoada de impressões recebidas anteriormente, mais que no estado normal não lhe era possivel reviver. Nos afogados, nas intoxicações pelo ópio e pela haschich, no estado de excitação maníaca mitigada, também se pode observar êsse mesmo estado. Fáto curioso tem se observado na fase pré-agônica, em que certas pessoas, inclusive psicopatas que durante os últimos anos da vida não haviam manifestado indicio da menor elaboração mental, recordam-se de casos ocorridos durante a existência, com precisão e lucidez.

Alguns psiquiatras se têm dedicado ạo estudo dos indivíduos em estado de transe mediúnico, chegando à conclusāo de que o fáto dessas pessoas repetirem frases em língua para êles estranha se explica por um fenômeno de hipermnésia. São pessoas que ouviram falar línguas estrangeiras na infância, sem fixar perfeitamente as palavras aprendidas. Destárte, no estado normal a evocação das mesmas não é possivel, enquanto que, em circunstâncias especiais, uma irrigação cerebral mais intensa póde despertar imagens mnésicas latentes, de que o próprio individuo ignorava ter conhecimento. E' a chamada criptomnésia.

DISMNESIAS. - Nestas formas há uma perversão da memória. As recordações se apresentam deturpadas e a evocação das mesmas se faz erroneamente, senão na sua totalidade, pelo menos em parte.

No grupo das dismnésias figura a chamada Ecmnésia, na qual o paciente tem uma visão panorâmica súbita do passado. Isso se observa quando há desdobramento da personalidade. 0 paciente por vezes mostra-se lúcido, bem orientado no meio e tempo, mas, ao se referir a certos e determinados fátos que constituem o núcleo principal das suas preo- 
cupagien. julgi cncontrar-se em outra época, referindo-se a pessuas ja falecidas, a localidades de onde há muito se afarlou.

Fenomeno que por longo tempo preocupou os fisiolopistas, psicólogos e psiquiatras foi a chamada alucinação do "já visto", "jii percebido", "já ouvido", "já sentido". Trata" de u'a modalidade da paramnésia, em que o doente, ao defrontar pela primcira vez com uma pessoa, ao descortinar um panorama jamais por cle apreciado, tem a convicção de estar diante de uma sensaça já anteriormente percebida. $P$. Janet descreve curiosa observaçio de u'a moça estrangeira por ile tratadi, que, sem nunca ter estado em París, ao peneirar pela primeira ve\% em sell consultório, pôs-se a examinar os quadros, os móveis, os objetos, perguntando desde quando haviam sido mudados os mesmos dos seus lugares, pois que da última vez que alí estivera a disposição dos móveis era outra. Entretanto, era absolutamente seguro ser aquela a primeira visita feita ao seu consultório.

Ribot cita vários casos idênticos. Fálret já havia assinalado a freqüência das chamadas pelos autores francêses alucinaçōes do "dejá vu" em doentes mentais de várias categorias, sobretudo nas psicoses alucinatórias crônicas. Quando essas impressões são muito numerosas e repetidas podem mesmo crinstituir um grupo de idéias delirantes denominado delírio palingnóstico - de palim - novo; gnóstico - conhecimento.

Outras vezes se nota exatamente o contrário, isto é, o paciente cada vez que se defronta com uma pessoa, com a qual ainda estivera na véspera, tem a certeza de não a ter visto antes. Tal se dá na presbiofrenia e na psicose de Kersakoff, quando há a perda da memória de fixação ou anterógrada, de forma que o doente se capacita de que realmente desconhece as pessoas e está pela primeira vez em lugar onde já de há muito se encọtra.

\section{LEI DA REGRESSÃO OU DA REVERSÃO DA MEMORIA DE RIBOT}

Ribot, no seu livro "Maladies de la Memoire", descreve como foi levado a fundamentar a lei que conserva o seu nome. Desde há muito, já na Grécia antiga havia sido assiDalado o fáto de certos velhos olvidarem as imagens mais recentes, as passo que se recordavam com grande abundân- 
cia de minúcias de fátos passados na juventude e na sua infancia. Contudo, a Ribot cabe o mérito de haver demonstrado operar-se, na velhice, o cancelamento das idéias, não de uma forma anárquica, ao acaso, mas sim obedecendo a uma determinada ordem. Pode a lei de Ribot ser sintetizada:

1) $O$ novo desaparece antes do velho.

2) Há, na perda da memória, um recuo no passado, que se opera progressiva e uniformemente.

3) As noções mais complexas são olvidadas primeiramente.

4) A marcha da amnésia segue do instável para o estável, das noçôes abstratas para as concretas.

Os sentimentos af etivos são os últimos a desaparecerem.

A lei da regressão da memória de Ribot pode ser facilmente verificada quando se acompanha a evolução da demência senil, das psicoses de involução. E' fáto conhecido o dos velhos olvidarem tudo quanto está próximo e se recordarem das cenas ocorridas na infância.

Esse fáto explica um dos principais caracteristicos da psicologia dos velhos, que é a tendência a denegrir o presente e exaltar o passado, a se tornarem rotineiros, a detestarem o progresso e as novidades, inacessíveis à sua compreensão, em virtude da esclerose cerebral que já não lhes permite a assimilação de novos conhecimentos. 0 cérebro, como a argila sêca, conserva o que se lhe imprimiu no período da plasticidade, mas já se não podem moldar outras formas. Dai o "Laudator tempori ati" a que nenhum velho escapa. Há neles a tendência a louvar o passado, a enaltecer os homens e as coisas do seu tempo, em que a vidă lhes sorria, em que tudo era fácil, os homens honestos, outros os sentimentos da honra e do dever. Com o evoluir da demência senil apagam-se as lembranças colhidas na idade madura e na adolescência, persistindo apenas as imagens registradas na infúncia. Confirma-se então o brocardo popular que os extremos se tocam, a velhice e a infância apresentam analogias entre si. 0 velho torna-se então egoista, só se preocupa com a sua pessôa, em virtude de renascerem não só as mesmas lembranças, mas também os mesmos sentimentos da infância, que o levam a convergir a sua preocupação tão sòmente para as necessidades materiais.

A lei de Ribot tem a sua contraprova no fáto verificado em certos velhos que, por um tratamento desintoxicante, re- 
cobram parte da sua memória, notando-se que os conhecimentos vio se restabelecendo, as lembranças vão surgindo scguindo a orden inversa da que foi observada no seu desaparecimento. Por tal forma que os últimos conhecimentos a se refazerem são os mais próximos e os primeiros os mais remotos. Igual fenómeno se observa com relação às noções - as mais concretas são as que se recompõem em primeiro lugar, para só depois se operar a reconstituição das imagens abstrátas. Esta contraprova pode ser feita também fora da deméncia senil, nas amnésias devidas aos traumatismos fisicos ou psíquicos, como tão bem demonstrou P. Janet.

Cono acabamos de ver, o estudo da memória oferece campo para interessantissimos estudos de psicologia e de psicopatologia do mais alto valor, os quais foram aqui apenas esboçados para se ter uma pálida idéia das faculdades mnésicas, que constituem o mais maravilhoso dote do espirito humano e o fator básico do progresso em todas as direçōes. 